\title{
Challenges Faced by Teachers in the Implementation of Guidance and Counselling in Eswatini Primary Schools
}

\author{
B. D. Sibandze ${ }^{1} \quad$ Racheal Mafumbate ${ }^{2 *}$ \\ 1.Nhlangano Central Primary School. Eswatini. \\ 2.University of Eswatini, Department of Educational Foundations and Management, Faculty of Education.
}

\begin{abstract}
Providing guidance and counselling in schools is one of the most important services a school has to have and it is the reason why the Ministry of Education and Training (MoET) introduced guidance and counselling in both primary and high schools of Eswatini. However, there are obstacles that affect the effective implementation of guidance and counselling in schools. Thus, there was a need to find out the challenges teachers face in the implementation of guidance and counselling in Eswatini primary schools. The study was a qualitative study and it employed a multiple case study design. There were 27 participants from the Shiselweni guidance and counselling pilot schools who were selected purposively. Data were collected through focus group discussions and in-depth interviews. A thematic analysis was used to analyse the data. The main findings of the study revealed that guidance and counselling is affected by role ambiguity for guidance and counselling teachers, lack of required resources and inadequate supervision. Therefore, there is a great need for the Ministry of Education and Training to develop clear policies for running and managing guidance and counselling services in schools.
\end{abstract}

Keywords: challenges, guidance and counselling, implementation, Primary school, Shiselweni,

DOI: $10.7176 / \mathrm{JEP} / 10-12-21$

Publication date: April $30^{\text {th }} 2019$

\section{Introduction}

Guidance and counselling in schools has been well received by most countries since it is a programme that is meant to help school going children to adjust meaningfully to the environment, develop the ability to set realistic goals and improve on total education programmes (Egbo, 2015). In essence, guidance and counselling combined with education provide opportunities for students to reach their full potential in the areas of educational, vocational, social and emotional development, hence, it is imperative for schools to consider the implementation of guidance and counselling (Lunenburg, 2010). Any guidance and counselling progrmmme is geared towards instilling problem solving skills and acquisition self- knowledge by students (Shumba, Mpofu, Seotlwe \& Montsi, 2011).

Considering the importance of guidance and counselling in schools, Eswatini has also embraced the idea of guidance and counselling in both primary and high schools. Despite the fact that the fundamental objective of a school guidance and counselling programme is to facilitate the total wholesome and fullest development of each student, in terms of enriching his or her intellectual, vocational, emotional, personal-social resources, guidance and counselling in schools is faced with a lot of challenges. Guidance and counselling teachers at high school have obstacles that hinder them from implementing the programme effectively (Shabangu, 2012). However, the existing literature is silent on the challenges faced by primary teachers in the implementation of guidance and counselling in Eswatini. Thus, there was a need to establish the challenges in the implementation of guidance and counselling in Shiselweni primary schools of Eswatini.

\section{Purpose and objective of the study}

The purpose of the study was to find out the challenges associated with the implementation of guidance and counselling in Shiselweni primary schools. The specific objectives were to:

1. Find out the challenges encountered by guidance and counselling teachers in the implementation of guidance and counselling in Shiselweni primary schools.

2. Establish strategies that can be used by guidance and counselling and teachers to combat the challenges in implementing guidance and counselling in Shiselweni primary schools.

\section{Theoretical framework}

The study was framed by Maslow's (1943) hierarchy of needs. This theory states that healthy human beings have a certain number of needs and are arranged in a hierarchy. Some needs are basic than others. Higher needs which are the needs that are at the top of the hierarchy, come into focus once the basic needs are met. A person whose basic needs are not met is not motivated to do anything. Instead, he becomes anxious. A person is able to reach the last level, which is the level of self-actualization and it is where a person reaches his or her fullest potential once the basic needs are met. Maslow asserts that if a person's needs are met, he/she turns his / her attention to self-actualization.

The researcher deems the application of this theory appropriate for this study because guidance and 
counselling teachers have needs that have to be met in order for them to deliver guidance and counselling services effectively. If the needs are not met, they become challenges which inhibit them from achieving their full potential. They become demotivated instead. If the working conditions can be improved, guidance and counselling in schools can improve drastically. The guidance and counselling programme can serve the purpose it was introduced for. The Ministry of Education and Training (MoET) and the school principals need to work collaboratively in addressing the challenges teachers face in the implementation of guidance and counselling.

\section{Literature review}

Studies have been carried with regard to challenges associated with the implementation of guidance and counselling in schools. Hearne, Geary and Martin (2017) found that the provision of guidance and counselling within the school system is increasingly becoming relevant for learning and development. However, it seems as everybody's and nobody's responsibility. This means that there is nobody who takes the responsibility of teaching guidance and counselling amongst teachers. In addition, most hours are timetabled for classroom teaching of curriculum other than guidance and counselling.

Sahin (2016) revealed that participants stated that guidance and counselling would drastically improve if they could receive good training since detailed counselling is required for psychological counsellors and that supervisors of counsellors should not be school principals. Sahin further alluded to the fact that the number of school counsellors should be sufficient and there should be adequate and appropriate facilities. Inadequate training in guidance and counselling and lack of enough resources such as guidance and counselling room, negative attitudes of students to go for counselling, lack of policy framework on guidance and counselling, lack of incentives, too much workload for counsellors leaving too little time for counselling are some of the challenges associated with the implementation of guidance and counselling (Cheruiyot, 2015).

On the other hand, Owino (2015) found that most guidance and counselling teachers said there were no guidelines that were followed in delivering guidance and counselling while others were not even sure whether there were guidelines or not. More, teachers complained about heavy teaching loads which do not allow them to consult with others on matters concerning the programme thus rendering the programme a failure. Some counsellors are self-critical in practice and have troubling reaction to clients since they do not know what to do in a counselling session (Pereira \& Rekha, 2017). Karatas and Kaya (2015) also stated that despite all job definitions for counselling, school counsellors sometimes have to do tasks that are not aligned with their professional responsibilities. This is because of prejudice of school administrators and teachers against guidance and counselling services.

\subsection{Strategies to combat challenges associated with the implementation of guidance and counselling}

Wambu and Fisher (2015) state that due to the wide array of challenges faced by counsellors in Kenyan schools, it is important for policy makers to design comprehensive guidance programmes that could clarify what school counsellors could do or should do and should see to it that school counsellors are employed and not appointed to merely fill up a position. Ruttoh (2015) stated that a guidance and counselling programme must be included in the school timetable and the school budget in order to minimize the challenges faced with programme. Salgong, Ngumi and Chege (2016) stated that teachers felt a great need for schools to provide facilities like counselling offices, magazines, audio and video tapes among others that would enhance the implementation of guidance and counselling in schools. On the issue of training teacher counsellors Shumba, Mpofu, Seotlwe and Montsi (2011) noted that primary school are teachers trained to teach curriculum subjects except guidance and counselling. The lack of training in teaching guidance and counselling raises the question of what their competencies are in this area.

\section{Methodology}

The study utilized a multiple case study design which is a design that involves two or more cases of the same phenomenon to get more varied evidence and cross examination. The study was conducted in three guidance and counselling pilot schools that are found in the Shiselweni region of Eswatini. A sample of 27 teachers who were general and guidance and counselling teachers was purposively selected for the study. Focus group discussions and in- depth interviews were used to collect data.

In this study the researcher made effort to maximize trustworthiness by ensuring credibility, transferability, dependability and conformability.

Ethical considerations were observed in this study to ensure that the rights of participants were not infringed. Permission to conduct the study was sought, participants were assured of confidentiality, anonymity was observed and participants were given the freedom to decide to participate in the study without interference.

A thematic data analysis by Clark and Braun was used to analyse data for this study. This is a method for identifying, analysing and reporting patters (themes) within data. Data were transcribed into written form in order to conduct a thematic analysis and to make the participants' comments useful and understandable. The researcher 
generated initial codes and searched for themes from the coded data by analysing the codes and considering how different codes combined to form a theme. Themes were then defined and named according to what each theme was all about.

\section{Findings and Discussions}

6.1 Challenges to implementation

Findings revealed that the ambiguous role of the guidance and counselling teacher, workload and time allocated for guidance and counselling are challenges in the effective implementation of guidance and counselling in primary schools.

\subsubsection{Guidance and counselling is extra work}

Participants stated that guidance and counselling is extra work for guidance and counselling teachers since they work as teachers and are expected to provide guidance and counselling services as well. Participants also stated that it is difficult to build a counselling relationship with a learner in a counselling session while in charge of his or her academic work. Even the guidance and counselling teacher is also affected as learners do not take her subjects seriously because they regard the teacher as a counsellor. One participant stated that:

The guidance and counselling teacher is used as a counsellor here at school on top of her school work. She is a teacher first before her role of being a counsellor. Sometimes when teachers and learners come for help, they find her in class teaching and that class is interrupted. Some of us are not aware of what to report and what not to report to the counsellor, except that we use her in behaviour problems, health issues and when learners have personal and academic problems (Participant \# 6, a female teacher from Case C).

The findings are consistent with Wambu and Fisher (2015) who pointed out that even though there were many counsellors in American schools, their role was unclear to the consumers of counselling services. The counsellors still have teaching responsibilities over and above their counselling duties which leaves counsellors with limited time to provide counselling services to students. In the same way Owino and Odera (2014) posited that the overload for counsellors in schools make them exhausted to practice the guidance and counselling programme.

\subsubsection{Heavy work load}

Guidance and counselling teachers complained that they work as curriculum teachers before they are guidance and counselling teachers. They strongly believe that the work load for guidance and counselling teachers is not properly handled because they have to be class and subject teachers before they are counsellors. They are given teaching periods that are equal to general teachers yet they are expected to plan and provide guidance and counselling activities and services. One participant stated that:

The work is too much yet we are not paid. It is even much better with sport teachers because they get E50.00 for being sport teachers. Some teachers come and disturb you in class so that you attend to a learner with a problem. It could be better if there was a guidance and counselling teacher who concentrated on guidance and counselling without having other subjects to teach (Participant \# 1, a male teacher from Case B).

Ondima, Nyamwage and Nyakan (2012) also observed that guidance and counselling teachers were not sufficiently relieved from their teaching duties to have adequate time to devote to guidance and counselling. Auni, Jechirchir,Odhiambo and Lyanda (2014) stated that teachers are over-loaded with the responsibility bestowed upon them and therefore need support from head teachers in relieving them in order to enable them to have more contact hours with student-clients.

\subsubsection{Insufficient time for guidance and counselling}

Findings also revealed that the time allocation for guidance and counselling is not enough. For instance, only one period is allocated for each grade per week. They introduce on the first day and when they come back on the next period the learners have forgotten what they did the last time thus delaying progress. In one school, guidance and counselling does even feature in the timetable, hence teachers use the sport time for the guidance and counselling session. Participants believe that the programme is not given enough time because it is not examinable and it is the reason why the staff and administration do not take it seriously. Some of the participants of the focus group discussion stated that:

We do have the guidance and counselling programme here at school, however, there is no time allocated for guidance and counselling in the school's time table and one wonders how we have to carry out the programme (Participant \# 4, a male teacher from Case A). There is 30 minutes for guidance and counselling for each and every grade ina week but the time is not enough to carry out the activities and services (Participant \# 5, a female teacher in Case C).

Not having a period in the school timetable is common in the implementation of guidance and counselling as the same was reported by Wambu and Fisher (2015) who found that guidance and counselling was offered during 
breaks, lunch breaks and after school in Kenya. Tiego (2015) also found out that lack of adequate time to handle and counsel the students, was a challenge in Kenyan high schools.

\subsubsection{Lack or limited required resources}

Participants also reported that there is lack or a limited required resource such as materials needed in carrying out the programme, funds and proper teacher counsellor training. The guidance and couselling teachers lack materials such as books, teaching aids and a counselling office which hinder effective service delivery. The guidance and counselling teachers were only given a syllabus which according to them is a skeleton without flesh and they have to scout for the right information to teach. One participants from the focus group discussion stated that:

Yes, the Ministry of Education and Training gave us a syllabus which we have to follow as one of us has said but we do have books we got from an organization called Girls Leading Our World and Boys Reaching Out (GLOW \& BRO) where we pick topics suitable for each and every grade following the syllabus we have (Participant \# 3, a female teacher from case $\mathrm{C}$ ).

In cases $\mathrm{B}$ and $\mathrm{C}$, counsellors share the classroom set aside for counselling with other teachers yet in case A, there is no class set aside for guidance and counselling and by so doing, confidentiality of learners is compromised. This finding is similar to Wambu and Fisher (2015) assertion who opined that in some schools, the school counsellor shared the office with other teaching staff, and consequently confidentiality of students' records can be easily compromised yet counsellors agreed that counselling should take place where there are no disruptions so that learners can be assured that no one can hear their conversations (Mbongo, Mowes \& Chata ,2016). Moreover, most schools in Kenya were not well organized in the implementation of guidance and counselling in terms of infrastructure (Ruttoh, 2015).

\subsubsection{Insufficient funds}

Findings further pointed out that funds are also an issue in the implementation of guidance and counselling. There are no funds allocated for guidance and counselling in the school budget and when guidance and counselling teachers ask for money to buy or do something, they are always told there is no money for guidance and counselling: One participant stated:

Another thing that is discouraging is that a learner reports his or her problem to the guidance and counselling teacher expecting to get help. Yet the guidance and counselling teacher is always told that there is no money for guidance and counselling. There is nothing she can do on her own without the financial support from the head teacher (Participant \# 1, a male teacher from Case B).

The findings are supported by Arowolo (2013) who opined that no meaningful services are cheap, for effective counselling, funds are needed. Funds are needed for the purchase of counselling materials like inventories, charts and also to equip the counsellors with tools for appraisal and placement. Chinonyelum (2013) also noted that the guidance and counselling programme was not well funded in Nigerian schools and where funds were available, very little was earmarked for guidance and counselling purposes.

Guidance and counselling teachers and general teachers from the three cases concurred that they do not have sufficient competence in providing the guidance and counselling programme. Few teachers were taken to several workshops on different occasions and were expected to do a step-down training for the benefit of the other teachers. They believe that the in-service workshops are important and would be beneficial if they were done to trained teachers or counsellors. Hence, they lack the necessary skills for the practice. They pointed out that lack of training of guidance and counselling teachers compromises the quality of the services provided. A participant from the focus group discussion was quoted saying:

I was forced into the programme, because I was just appointed and I do not have any training except for the short seminars and workshops I attended which were organized by different nongovernmental organizations (Participant \# 4, a female teacher from Case B).

This finding is in contrary with Arowolo (2013) who asserted that seminars and workshops were enough to enhance counsellors' professionalism. According to Arowolo, it is in these workshops and seminars where new development in counselling is made known. However, Tiego and Kamore (2015) supported the guidance and counselling teachers by stating that quality training is important in motivating school counsellors by increasing their self- efficacy in offering quality guidance and counselling services

Lack of guidance and counselling inspectors exposed at primary school was also cited as a problem for the effective implementation of the guidance and counselling since most of the guidance and counselling inspectors are high school teachers who do not have a clear understanding of what is happening in primary schools. They are not aware of what primary teachers and learners are grappling with since they lack the experience of being primary school teachers. A participant said this in a focus group discussion:

There is a problem with the inspectors because most of them are high school teachers who do not have the experience of being primary school teachers and they do not have a clear picture of what is happening at primary level. They do not make a follow up and they fail to come up with activities that can be suitable for primary schools. (Participant \# 3, a female teacher from Case 
C).

This is consistent with Mapfumo and Nkoma (2013) who indicated that school heads in Mutare Urban high schools in Zimbabwe reported minimal supervision of the programme with little support from the school inspectors. Contrarily, Mbongo, Mowes and Chata (2016) found out that Regional School Counsellors in Ohangwena region of Namibia were quick to respond and render help when asked for help and that teacher counsellors felt motivated to do their work as they did not feel isolated and did not lack support.

\section{6,2 Strategies to combat challenges in the implementation of guidance and counselling 6.2.1 Provision of equipment and working materials}

Most of the participants from all the cases reported that equipment; resources and working materials used in the implementation of guidance and counselling are improvised by the school counsellors and other teachers who take part in the guidance and counselling programme since there is not much the counselling departments received from the Ministry of Education and Training and the school's administration. Thus the participants suggested that the Ministry of Education and Training must provide the required equipment and materials needed in schools for guidance and counselling and that the school guidance and counselling programme must have a budget allocation just like any other practical subject. Boitti (2016) also noted that the guidance and counselling programmes need adequate funding that will enable to put up infrastructure and purchase the required facilities.

6.2.2 Policy on guidance and counselling

The findings also revealed that participants suggested that it is imperative for the Ministry of Education and Training to provide schools with comprehensive guidance and counselling policy that could clarify what counsellors could do or not do to make the differences in the lives of the learners. Policies on guidance and counselling programme are not clear on the role of the guidance and counselling teacher, teachers and the administration. Participants stated that clarity of the policy would give the guidance and counselling programme the value it deserves. One participant from the interviews stated that:

It is very difficult to be a guidance and counselling teacher here at primary school because we are expected to carry out the programme without the necessary policies that will enable us to do so. For instance, when you ask for money to do something in the programme, the head teacher says there is no money allocated for guidance and counselling. Other practical subjects have been accommodated in the school budget (Participant \# 4, a female teacher, Case B).

In similar vein Gudyanga, Wadesango and Gudyanga (2015) noted that when there is a clear and well communicated policy vision, there is the basis for clear planning. On the other hand, Tiego and Kamore (2015) stated that when policies are developed but not well articulated to the users, the result is poor implementation.

6.2.3 Having experienced regional inspectors for guidance and counselling

Participants had a feeling that there was a need for a regional inspector who had an experience of being a primary school teacher since most of the ones they had in the regional offices had never taught at primary school. They believed that this inspector would have a clear understanding of what primary school learners as well as teachers were grappling with. More so, provide the necessary assistance required at primary schools. One participant from an in-depth interview said:

We really need primary school inspectors, who once taught at primary and are aware of the needs of primary school teachers and learners. This can only be possible if the policies governing the planning and implementation of guidance and counselling are clear (Participant \# 8, a female teacher from Case C).

The findings are in line with Mbongo, Mowes and Chata (2016) who stated that regional school inspectors in Namibia took their responsibilities of overseeing the implementation of guidance and counselling in schools very seriously as they were once teachers.

\subsubsection{Adjustment of time allocated for guidance and counselling}

Findings also revealed that the participants suggested that time allocated for the guidance and counselling programme must be more than the 30 minutes because it is not enough. In Case A there was a need for the timetabled guidance and counselling period which would enable them to effectively implement the programme. One participant stated that:

The 30 minutes period we have is not enough for teaching guidance and counselling, hence, the Ministry of Education and Training has to extend the time (Participant \# 8, a female teacher from Case C).

The findings are in consistent with Shumba et al. (2011) who posited that the lack of time is another factor which hinders the proper implementation of guidance and counselling in schools and therefore, there is a great need to increase the time allocated for guidance and counselling in schools.

6.2.5 Incentives for teaching guidance and counselling

Guidance and counselling teachers in all the schools pleaded for incentives since they feel demotivated to carry 
on with the programme as they are not rewarded for the extra work they do yet the programme is very important. One participant said this in an in-depth interview:

It discouraging to work as a guidance and counselling teacher because we do not get incentives for the hard work that we do. Sport teachers are better than us because there is money they get for being sport teachers yet sports are done on certain times of the year. Guidance and counselling is always there throughout the year (Participant \# 3, a female teacher, Case C).

Tiego and Kamore (2015) agreed with the findings by stating that incentives for teachers are important to ensure that they are committed and effective in offering quality guidance and counselling services. Even in Zimbabwe teachers complained about their salaries and expected a reward of some sort since they viewed guidance and counselling as an unnecessary overload to their work (Gudyanga, Wadesango \& Gudyanga, 2015).

\subsubsection{Proper training for guidance and counselling}

On the issue of lack of training, participants suggested that guidance and counselling must be a major course just like other courses done at college. One participant from an in-depth interview in Case A had this to say: I have a feeling that guidance and counselling should be introduced at college level just like other practical subjects because it is not fair for that teacher who will be expected to execute duties she does not have expertise on (Participant \#2 from an in-depth interview in Case A).

The teachers' assertion is in line with Manderi (2013) who reported that teacher counsellors not being trained make most to have wrong perceptions toward guidance and counselling as they lack the necessary skills that are required. Owino and Odera (2014) pointed out the importance of training by stating that guidance and counselling needs psychology and skills to be able to apply on clients and it is only possible through training. This is an indication that guidance and counselling teachers need to be well trained and be knowledgeable to perform their work confidently.

\subsubsection{Collaborative partnership with parents}

Finally, findings of the study revealed that there is a need for collaborative partnership with parents for learners who may need prolonged services. Parents should be made aware of the programme to avoid conflict between them and teachers. The relationship between teachers and parents is affected since learners tend to depend more on guidance and counselling teachers than their parents. The learners are more open to guidance and counselling teachers than they are to their parents. Whereas partnership between the two parties (teachers and parents) could help provide room for dialogue and consequently yield good results. The following is an example of a quote from participants from an in-depth interview:

Parents have not been well informed about the programme by the Ministry of Education and Training. Some parents take this as an invasion of privacy when we try to communicate with them about their children's welfare. They do not take the programme seriously even though our head teacher gives us the platform to say something during a parents' meeting. More so, because it does not appear on the school's academic performance report (Participant \# 6, a female teacher from Case B).

Oye, Obi, Mohd and Bernice (2012) made a similar observation and concluded that inclusion of parents can help to measure the progress of guidance and counselling as they can mention the problems of their children. Boitti (2016) also noted that it is important that parents are provided with necessary support, not only from the school administration but also from parents.

\section{Conclusion and recommendations}

Guidance and counselling teachers face the following challenges during the implementation of guidance and counselling: lack of funds, inadequate time allocation, lack of training, lack of supervision, role ambiguity, a heavy workload and lack of collaborative effort among stakeholders. Therefore, the study recommended that the Ministry of Education and Training should ensure that each school has a full time guidance and counselling teacher who will only specialize on providing guidance and counselling services and that there must be a timetabled guidance and counselling period for each and every grade in a school. Funds for carrying out the programme must be on the yearly school budget to ensure its continuity and success. Lastly, the Ministry of Education and Training should visit schools on regular basis to assess how the programme is implemented in schools.

\section{References}

Arowolo, D. O. (2013). Counselors' perception of problems facing guidance and counseling services. Journal of Education and Practice, (4) 115-118).

Auni, R. T., Jechirchir, S. R. , Odhiambo, O. R, Lyanda, N. J. (2014). Determinates of

guidance and counseling programme in addressing Students Social Adjustment in Secondary Schools in Siaya

District, Kenya. International Journal of Humanities and Social Science, 4 (4) 69-87.

Boitt, M. L. J (2016). Evaluation of the challenges in the implementation of guidance and 
Counselling programme in Baringo County secondary schools, Kenya. Journal of Education and Practice, 7 (30) 27-34.

Cheruiyot, D. K. (2015). Guidance and counselling: What is the level of human and physical preparedness in providing effective services in secondary schools in Bureti Sub County, Kericho, Kenya? Journal of Education and Practice, 6 (23) 132-143.

Chinolenyum, E. A. (2013). The role of guidance and counseling in effective teaching and learning in schools: The Nigerian perspective (Master's thesis). Enugu State University of Science and Technology, Nigeria.

Egbo, A. C. (2013). The role of guidance and counseling in effective teaching and learning in Schools: The Nigerian perspective (Master's thesis). Enugu State University of Science and Technology, Nigeria.

Egbo, J. O. E. (2015). Need for guidance and counseling at primary school level: Early Intervention strategies for school children. British Journal of Counseling, (6) 1-

Gudyanga, E., Wadesango, N., Manzira L. R. \& Gudyanga, A. (2015). Implementation of guidance and counselling in schools in Chinhoyi Urban. International Journal of Educational Science, (1) 44-49.

Hearnen, L. Geary, J. \& Martin, N. (2017). Guidance and counselling as a whole school Responsibility in the Irish post primary sector in Ireland. British Journal of guidance Counselling, 45 (2) 138-152.

Kamore, S. K. \& Tiego, P. M. (2013). What hinders guidance and counseling' effectiveness in enhancing discipline in high schools in Mranga's County Kenya. International Journal of Science and Research, (4) 115-118.

Karatas, K. \& Kaya, I. (2015). An investigation of the perceptions of school administrators towards the roles and duties of school counsellors. Eurasian Journal of Educational Research, (61) 181-198.

Mapfumo, J., \& Nkoma, E. (2013). The state of the guidance and counseling programmes in high schools in Manicaland, Zimbabwe. International Journal of Scientific Research in Education, (2) 100-116.

Manderi, M. L. (2013). Perceptions of teachers and students towards guidance and counseling services in public secondary schools in Ongate Rongai and Ngong Zones of Kajiado North District kajiado County-Kenya, faculty of Science, CUEA. Kenya.

Mbongo, E., Mowes, A, Chata, C. (2016). Factors impacting the implementation of the guidance and counselling Services in secondary schools in the Ohangwena Region of Namibia. International Journal for Innovation Education and Research, 4 (5) 2411-3123.

Ministry of Education and Training (2011). Sector policy: Mbabane, Eswatini Government.

Ondima, P. C. , Mokogi, H. , Ombaba, S. \& Osoro, G. N. (2013). Effectiveness of guidance and counselling programme in enhancing students' academic, career and personal competencies. A case of secondary schools in Nyamira District, Kenya. Journal of Education and Practice, (4) 50-57.

Owino, E. A. (2015). Assessment of service delivery in guidance and counselling units in

selected Secondary schools in Eldorent Municipality, Kenya. Journal of Education and Practice, 6 (19) 29-42.

Owino, J., \& Odera, F. Y. (2014). Attitudes of teachers towards guidance and counselling in Primary schools in Kisuni, West Sub County. International Journal of Humanities and Social Science Invention, (3 ) 55-62.

Oye, N. D., Obi, M. C. , Mohd, T. N. , Bernice, A. (2012). Guidance and counselling in Nigerian secondary schools: The role of ICT. Modern Education and Computer Science, (8) 26-33.

Ruttoh, M. J. K. (2015). Planning and implementation of guidance and counseling activities in Secondary schools: A case of Karaminy Division of Keiyo District, Kenya. Journal of Education and practice, (6) 101-112.

Pereira, M. \& Rekha, S. (2017) Problems, difficulties and challenges faced by counsellors. The International Journal of Indian Psychology, 2349-3429.

Salgong, V. K., Ngumi, O. \& Chege, K. (2016). The role of guidance and counselling in enhancing student discipline in Secondaary in Koibatek District. Journal of Education and Practice, (7) 13, 142-151.

Sahin,F.Y. (2016). School counsellor's assessment of the psychological counselling and guidanceServices they offer at their schools. Kastamonu Egitim Dergisi, 24 (1) 281-298.

Shabangu, S. (2012). An examination of the extent of the implementation of the career

guidance Programme in high schools in the Manzini city, master's thesis, University of Eswatini, Kwaluseni. Eswatini.

Shumba, A., Mpofu, E., \& Seotlwe, M. , Montsi, M. R. (2011). Perceived challenges for implementing the guidance and counselling subject in Botswana primary schools. J Soc Sci, (1), 1-11.

Tiego, P. M. \& Kamore, S. K. (2015). Efficiency of guidance and counseling departments in promotion of Discipline in high schools in Kiambu County, Kenya. Academic Journal Interdisciplinary Studies, (4) 301308.

Wambu, G.W. \& Fisher, T.A. (2015). School guidance and counseling in Kenya: Historical development, current status and future prospects. Journal of Education and Practice, 11 (6) 93-104. 